\title{
Sustained safety and clinical performance of a drug-eluting absorbable metal scaffold up to 24 months: pooled outcomes of BIOSOLVE-II and BIOSOLVE-III
}

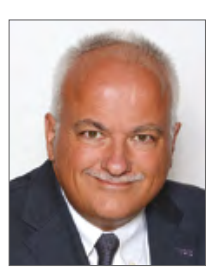

\begin{abstract}
1. Medical Clinic I, Städtische Kliniken Neuss, Lukaskrankenhaus GmbH, Neuss, Germany; 2. Department of Cardiology, Vivantes Klinikum im Friedrichshain and Vivantes Klinikum Am Urban, Berlin, Germany, and Department of Cardiology, Universitätsmedizin Rostock, Rostock, Germany; 3. Department of Cardiology, Vivantes Klinikum im Friedrichshain, Berlin, Germany; 4. Instituto de Cardiologia Dante Pazzanese, Sao Paulo, Brazil, 5. Herzzentrum Segeberger Kliniken GmbH, Bad Segeberg, Germany; 6. Instituto do Coração - HCFMUSP, University of Sao Paulo, Sao Paulo, Brazil; 7. Thoraxcenter, Erasmus Medical Center, Rotterdam, the Netherlands; 8. Interventional Cardiology, Middelheim Hospital, Antwerp, Belgium; 9. Medisch Spectrum Twente, Thoraxcentrum Twente, Enschede, the Netherlands; 10. Aarhus University Hospital, Skejby, Aarhus, Denmark; 11. Cardiovascular Research Center Aalst, OLV Hospital, Aalst, Belgium; 12. Interventional Cardiology, MedStar Washington Hospital Center, Washington, DC, USA
\end{abstract}

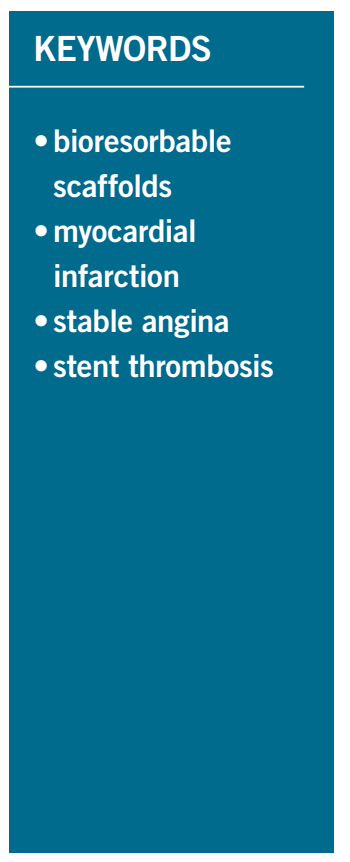

\begin{abstract}
Aims: We aimed to assess the safety and performance of the DREAMS $2 \mathrm{G}$ scaffold up to 24 months post implant.

Methods and results: The present study population comprises a total of 184 patients with 189 lesions who were enrolled in the prospective, multicentre BIOSOLVE-II and BIOSOLVE-III trials. Clinical followup was scheduled at one, six, 12, 24 and 36 months. The present report includes pooled follow-up data at six months and BIOSOLVE-II data at 24 months. Patients were $65.5 \pm 10.8$ years old, and lesions were $12.5 \pm 5.1 \mathrm{~mm}$ long with reference diameters of $2.7 \pm 0.4 \mathrm{~mm}$. Procedural success was obtained in $97.8 \%$. At six months, the composite clinical endpoint target lesion failure was 3.3\% (95\% CI: 1.2-7.1), based on two cardiac deaths $(1.1 \%$, one unknown and one not device-related), one target vessel myocardial infarction $(0.6 \%)$, and three clinically driven target lesion revascularisations (1.7\%). For BIOSOLVE-II at 24 months, the target lesion failure rate was $5.9 \%$ (95\% CI: 2.4-11.8), based on two cardiac deaths (1.7\%), one target vessel myocardial infarction $(0.9 \%)$ and four target lesion revascularisations $(3.4 \%)$. There was no definite or probable scaffold thrombosis.
\end{abstract}

Conclusions: The present analysis provides additional evidence on the safety of a drug-eluting absorbable metal scaffold with promising clinical outcomes up to 24 months and absence of definite or probable scaffold thrombosis.

*Corresponding author: Medical Clinic I, Städtische Kliniken Neuss, Lukaskrankenhaus GmbH, Preußenstraße 84, 41464 Neuss, Germany.E-mail: mhaude@lukasneuss.de 


\section{Abbreviations}

$\begin{array}{ll}\text { BRS } & \text { bioresorbable scaffold } \\ \text { DAPT } & \begin{array}{l}\text { dual antiplatelet therapy } \\ \text { drug-eluting stent }\end{array} \\ \text { DES } & \text { drug-eluting absorbable metal/magnesium scaffold } \\ \text { DREAMS } 2 \text { G } & \text { second generation } \\ & \text { optical coherence tomography } \\ \text { OCT } & \text { percutaneous coronary intervention } \\ \text { PCI } & \text { poly-L-lactic acid } \\ \text { PLLA } & \text { target lesion failure } \\ \text { TLF } & \text { target lesion revascularisation }\end{array}$

\section{Introduction}

Bioresorbable vascular scaffolds (BRS) have been developed to overcome limitations of bare metal and drug-eluting stents (DES), in particular to avoid creation of permanently caged vessel segments, chronic vessel wall inflammation or long-term stent crushing and fractures. Furthermore, BRS provide the option of non-invasive vessel lumen imaging by magnetic resonance or computed tomography and facilitate surgical or percutaneous repeat coronary revascularisation ${ }^{1,2}$.

Currently, three CE-marked drug-eluting BRS are available which are based on two different concepts of bioresorption: the polymeric Absorb (Abbott Vascular, Santa Clara, CA, USA) and DESolve $^{\circledR}$ (Elixir Medical, Sunnyvale, CA, USA) scaffolds and the metal DREAMS 2G scaffold (Magmaris; Biotronik, Bülach, Switzerland).

The sirolimus-eluting absorbable metal scaffold DREAMS $2 \mathrm{G}$ is built on the experience gained from its predecessors, the bare absorbable metal scaffold (AMS) and the paclitaxel-eluting DREAMS $1 \mathrm{G}$ (Biotronik). Both devices were tested in the PROGRESS and BIOSOLVE-I studies. There was no target lesion failure (TLF) beyond 12-month follow-up and no scaffold thrombosis. In addition, in the few patients with angiographic follow-up beyond one year, angiographic parameters tended to improve. However, late lumen loss at early follow-up was unacceptable, showing that a prolonged scaffolding time was required $^{3,4}$. Hence, DREAMS $2 \mathrm{G}$ was developed with a modified magnesium backbone, allowing a longer scaffolding time due to its slower degradation. Furthermore, the drug-polymer combination was modified to sirolimus/PLLA, the same combination that is used for the biodegradable Orsiro DES (Biotronik) with excellent clinical results ${ }^{5,6}$.

DREAMS $2 \mathrm{G}$ was first tested in the BIOSOLVE-II study with favourable 12-month outcomes ${ }^{7}$. However, as the true benefit of absorbable scaffolds is expected long-term, data beyond the resorption period are essential. This is even more necessary, as reports signalling very late thrombosis after implantation of the Absorb scaffold have been published recently ${ }^{8-10}$. We therefore assessed the safety and performance of DREAMS $2 \mathrm{G}$ in BIOSOLVE-II at 24 months. To provide additional data on a larger number of patients, we pooled the six-month results of BIOSOLVE-II with those of the BIOSOLVE-III study.

\section{Methods \\ STUDY DESIGN AND POPULATION}

The design of the BIOSOLVE-II study has been previously described $^{7,11}$. BIOSOLVE-II and BIOSOLVE-III are both prospective, multicentre studies to evaluate the safety and performance of DREAMS 2G. BIOSOLVE-II is conducted in 13 institutions in Europe, South America and Asia, and BIOSOLVE-III in eight institutions in Europe.

Both studies comply with the Declaration of Helsinki, Good Clinical Practice, ISO14155, and were approved by the institutional ethics committees. All patients provided written informed consent.

The main patient inclusion criteria were: stable or unstable angina or documented silent ischaemia, a maximum of two single de novo lesions in two separate coronary arteries, reference vessel diameter of 2.2-3.7 mm for device diameters of $2.5 \mathrm{~mm}$ to $3.5 \mathrm{~mm}$, lesion length $\leq 21 \mathrm{~mm}$, and a diameter stenosis $\geq 50 \%$ and $<100 \%$. The main exclusion criteria were: thrombus in the target vessel, severe calcification, three-vessel disease, ostial target lesions within $5 \mathrm{~mm}$ of the vessel origin, target lesions involving a side branch $>2.0 \mathrm{~mm}$, target lesion located in or supplied by an arterial or venous bypass graft, and unsuccessful predilatation. The full lists of inclusion and exclusion criteria can be accessed at ClinicalTrials.gov (NCT01960504 and NCT02716220).

Clinical follow-up was planned at one, six and 12 months, and annually thereafter up to three years. Angiographic follow-up was scheduled at six months for BIOSOLVE-II and (to allow an angiographic analysis at the end of the absorption period) at 12 months for BIOSOLVE-III. BIOSOLVE-II included additional imaging with intravascular ultrasound and optical coherence tomography (OCT); these outcomes have been reported ${ }^{7,11}$.

\section{STUDY DEVICE}

DREAMS $2 \mathrm{G}$ has been described previously ${ }^{7,11,12}$. In brief, it consists of a balloon-expandable bioresorbable metal scaffold made from a magnesium alloy, premounted on a rapid exchange delivery system. The struts are $150 \mu \mathrm{m}$ thick, have a width of $150 \mu \mathrm{m}$, and are laser-polished, and their surface is completely coated with bioresorbable PLLA that elutes sirolimus. The scaffold was available in diameters of 2.5,3.0, and $3.5 \mathrm{~mm}$ and lengths of 20 and $25 \mathrm{~mm}$ for BIOSOLVE-II, and diameters of 3.0 and $3.5 \mathrm{~mm}$, and lengths of 15, 20 and $25 \mathrm{~mm}$ for BIOSOLVE-III.

\section{ENDPOINTS}

The primary endpoints were late lumen loss at six-month follow-up (BIOSOLVE-II) and procedure success (BIOSOLVE-III). Procedure success was defined as final diameter stenosis of $<30 \%$ by quantitative coronary angiography without occurrence of inhospital death, Q-wave or non-Q-wave myocardial infarction or repeat revascularisation of the target lesion. Secondary endpoints were target lesion failure (TLF), a composite of cardiac death, target vessel myocardial infarction ${ }^{13}$, or clinically driven target lesion revascularisation (TLR), and scaffold thrombosis ${ }^{14}$. Secondary angiographic endpoints were reported previously ${ }^{7,11}$. 
A clinical events committee adjudicated all adverse events, and angiographic data were obtained from analyses of an independent core laboratory.

\section{PROCEDURE}

DREAMS $2 \mathrm{G}$ was implanted after a mandatory predilatation. The size of the predilatation balloon had to be $\leq 0.5 \mathrm{~mm}$ smaller than the reference vessel diameter but not larger than the reference vessel; its length had to be shorter than or the same as the lesion length.

Only one study device per lesion was allowed, although in bailout situations a second DREAMS $2 \mathrm{G}$ could be used and, in case of failure, an Orsiro DES. Post-dilatation could be performed at the discretion of the investigator, but the maximum inner diameter of the DREAMS $2 \mathrm{G}$ (as indicated on the label) was not permitted to be exceeded. In addition, the post-dilatation balloon had to be shorter than the scaffold. Dual antiplatelet therapy was recommended for a minimum of six months.

\section{STATISTICAL ANALYSIS}

Data are presented using descriptive statistical methods. For continuous variables, means \pm standard deviations are presented. For categorical data, absolute and relative frequencies are reported. When appropriate, 95\% confidence intervals were calculated. All statistical analyses were performed with SAS 9.3 (SAS Institute Inc., Cary, NC, USA).

\section{Results}

Between October 2013 and May 2015, 123 patients were enrolled in the BIOSOLVE-II study and, between March and September 2016, 61 patients in BIOSOLVE-III. In two BIOSOLVE-II patients, DREAMS $2 \mathrm{G}$ could not be implanted due to insufficient predilatation; these patients were only counted for procedure success but excluded from follow-up. Treatment of two lesions was performed in five patients, resulting in 189 lesions overall. Follow-up data were available for 180/182 BIOSOLVE-II and BIOSOLVE-III patients at six months $(98.9 \%)$ and for $120 / 121$ BIOSOLVE-II patients at 24 months (99.2\%) (Figure 1).

Baseline characteristics are listed in Table 1. Patients were $65.5 \pm 10.8$ years old, $63.6 \%(117 / 184)$ were male, $79.3 \%(146 / 184)$ had hypertension and $25.0 \%(46 / 184)$ were diabetics.

Vessels were $12.5 \pm 5.1 \mathrm{~mm}$ long with a mean reference diameter of $2.7 \pm 0.4 \mathrm{~mm}$. Mandatory predilatation was performed in all lesions. One to five inflations per balloon were performed (mean $1.5 \pm 0.9)$, and in 28 lesions (14.8\%) more than one predilatation balloon was needed. Predilatation balloons were $2.9 \pm 0.4 \mathrm{~mm}$ in diameter, ranging from 2 to $4 \mathrm{~mm}$, and the maximal pressure applied was $14.7 \pm 4.2 \mathrm{~atm}$, ranging from 4 to $26 \mathrm{~atm}$. More than one scaffold was implanted in seven patients (six for dissections, one as the original scaffold was too short to cover the lesion), and post-dilatation of scaffolds was performed in $69.0 \%$. Procedure success was achieved in $97.8 \%$ (180/184).

At baseline, stable angina was present in $75.0 \%(138 / 184)$ and unstable and documented silent ischaemia in $12.5 \%(23 / 184)$ each.

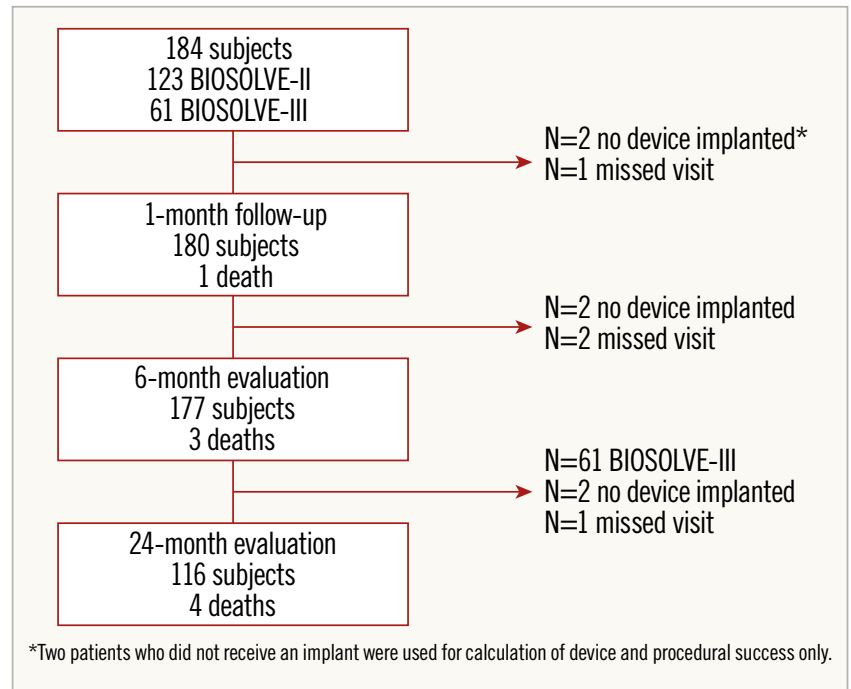

Figure 1. Study flow chart. Two patients of BIOSOLVE-II did not receive an implant and were counted for procedural success only.

At one month, 94.4\% (170/180) of patients were symptom-free; the remaining patients had stable angina. At six months, 88.2\% $(149 / 169)$ of patients were symptom-free while $9.5 \%$ had stable angina, $1.8 \%$ unstable angina and $0.6 \%$ documented silent ischaemia. Dual antiplatelet therapy was stopped in $2.7 \%$ prior to six months and in $86 \%$ prior to 24 months.

Target lesion failure at six months occurred in six patients $3.3 \%$ [95\% CI: 1.2-7.1]), consisting of two cardiac deaths $(1.1 \%, 95 \%$ CI: $0.1-3.9])$, one target vessel myocardial infarction $(0.6 \%[95 \%$ CI: $0.0-3.0])$, and three clinically driven TLR (1.7\% [95\% CI: $0.3-$ 4.8\%]) (Table 2). Figure 2 presents the case with TLR at day 84. Data beyond six months are available for the BIOSOLVE-II population only. Between six and 24 months, one additional cardiac death and two additional clinically driven TLR occurred, resulting in a TLF rate of $5.9 \%(n=7$ [95\% CI: 2.4-11.8]). Details of TLF events are provided in Table 3. No definite or probable scaffold thrombosis was observed. Figure $\mathbf{3}$ presents the case of a patient who already had serial imaging follow-up up to three years.

\section{Discussion}

This is the first report of DREAMS $2 \mathrm{G}$ with data up to two years. These data are particularly important as approximately $95 \%$ of the magnesium scaffold is expected to be absorbed within 12 months $^{11}$. The main findings of our series are low TLF rates at six and 24 months comparable to conventional DES, and the absence of definite or probable scaffold thrombosis.

The incidence of TLF, a composite of cardiac death, target vessel myocardial infarction or clinically driven TLR, was 3.3\% at six months, which is similar to the rate of $3.3 \%$ for the DESolve BRS ${ }^{15}$. In a recent meta-analysis of more than 8,000 Absorb BRS with a mean follow-up time of six months, cardiac death occurred in $0.6 \%$, myocardial infarction in $2.1 \%$ and TLR in $2.0 \%$ of patients ${ }^{16}$, compared to $1.1 \%, 0.6 \%$ and $1.7 \%$ in DREAMS $2 \mathrm{G}$ in our present series. 
Table 1. Baseline clinical and lesion characteristics.

\begin{tabular}{|c|c|}
\hline Patients & $N=184$ \\
\hline Mean age, years & $65.5 \pm 10.8$ \\
\hline Male gender & $117(63.6)$ \\
\hline Hypertension & $146(79.3)$ \\
\hline Hyperlipidaemia & $114(62.0)$ \\
\hline Diabetes & $46(25.0)$ \\
\hline History of smoking & $102(55.4)$ \\
\hline Previous percutaneous coronary interventions & $76(41.3)$ \\
\hline CABG & $9(7.5)$ \\
\hline History of myocardial infarction & $42(22.8)$ \\
\hline Renal disease & $15(8.2)$ \\
\hline Congestive heart failure & $23(12.5)$ \\
\hline History of stroke or TIA & $11(6.0)$ \\
\hline Cancer & $17(9.2)$ \\
\hline Lesions $^{a}$ & $N=189$ \\
\hline Mean lesion length, $\mathrm{mm}, \mathrm{N}=186$ & $\begin{array}{c}12.5 \pm 5.1 \\
{[11.8-13.3]}\end{array}$ \\
\hline Mean reference vessel diameter, $\mathrm{mm}, \mathrm{N}=186$ & $\begin{array}{c}2.7 \pm 0.4 \\
{[2.6-2.8]}\end{array}$ \\
\hline Diameter stenosis, $\%, \mathrm{~N}=182$ & $\begin{array}{c}53.9 \pm 11.3 \\
{[52.3-55.6]}\end{array}$ \\
\hline \multicolumn{2}{|l|}{ Target vessel, $\mathrm{N}=189$} \\
\hline Left anterior descending & $78(41.3)$ \\
\hline Right coronary artery & 64 (33.9) \\
\hline Left circumflex & $44(23.3)$ \\
\hline Ramus intermedius & $3(1.6)$ \\
\hline AHA/ACC classification type $B 2 / C, N=188$ & $116(61.7)$ \\
\hline Moderate-to-severe calcification, $\mathrm{N}=188$ & $29(15.4)$ \\
\hline Moderate to excessive vessel tortuosity, $\mathrm{N}=188$ & $50(26.6)$ \\
\hline Bifurcation involved, $\mathrm{N}=188$ & $15(8.0)$ \\
\hline Thrombus present, $\mathrm{N}=187$ & $4(2.1)$ \\
\hline \multicolumn{2}{|c|}{$\begin{array}{l}\text { Data are shown as mean } \pm \mathrm{SD} \text { or } \mathrm{n}(\%),[95 \% \mathrm{Cl}] .{ }^{\text {a }} \text { per core laboratory } \\
\text { assessment. AHA/ACC: American Heart Association/American College of } \\
\text { Cardiology; CABG: coronary artery bypass graft; TIA: transient ischaemic } \\
\text { attack }\end{array}$} \\
\hline
\end{tabular}

Table 2. Clinical outcomes at $\mathbf{3 0}$ days, 6 and 24 months.

\begin{tabular}{|c|c|c|c|}
\hline & \multicolumn{2}{|c|}{ BIOSOLVE-II and III } & \multirow{2}{*}{$\frac{\text { BIOSOLVE-II }}{24 \text { months }}$} \\
\hline & 30 days & 6 months & \\
\hline Target lesion failure & $2(1.1)$ & $6(3.3)$ & $7(5.9)$ \\
\hline Cardiac death & $1(0.6)$ & $2(1.1)$ & $2(1.7)$ \\
\hline TV myocardial infarction & $1(0.6)$ & $1(0.6)$ & $1(0.9)$ \\
\hline Clinically driven TLR & $0(0.0)$ & $3(1.7)$ & $4(3.4)$ \\
\hline Coronary artery bypass graft & $0(0.0)$ & $0(0.0)$ & $0(0.0)$ \\
\hline Death & $1(0.6)$ & $3(1.7)$ & $4(3.3)$ \\
\hline Myocardial infarction & $1(0.6)$ & $1(0.6)$ & $1(0.9)$ \\
\hline Clinically driven TVR & $0(0.0)$ & $3(1.7)$ & $6(5.2)$ \\
\hline $\begin{array}{l}\text { Scaffold thrombosis } \\
\text { Definite or probable }\end{array}$ & $0(0.0)$ & $0(0.0)$ & $0(0.0)$ \\
\hline
\end{tabular}

Data are shown as $n(\%)$. TLR: target lesion revascularisation; TV: target vessel; TVR: target vessel revascularisation
At 24 months, we found a TLF rate of $5.9 \%$ in DREAMS $2 \mathrm{G}$, which compares favourably with the TLF rate for DESolve $(7.4 \%)$ in the DESolve Nx trial ${ }^{15}$. In the ABSORB Japan, ABSORB II, ABSORB III, and AIDA studies, 24-month TLF rates for the Absorb BRS were $7.3 \%, 7.0 \%, 11.0 \%$, and $10.3 \%$, respectively. In comparison, the TLF rates for the comparator, an everolimuseluting cobalt-chromium stent, were $3.8 \%, 3.0 \%, 7.9 \%$, and $8.9 \%$ in the four aforementioned trials, respectively ${ }^{10,17-19}$.

The ESC-EAPCI report on the evaluation of coronary stents reported the following average event rates for new-generation DES at nine to 12 months $^{20}$ : cardiac death $1.0 \%$, myocardial infarction $2.89 \%$, TLR $2.91 \%$ and definite stent thrombosis $0.47 \%$. The six- and even 24-month data of DREAMS $2 \mathrm{G}$ are comparable. In particular, the cardiac death rate was $1.1 \%$ at six months for the pooled analysis and $1.7 \%$ at 24 months for BIOSOLVE-II, while the corresponding rates of myocardial infarction were $0.6 \%$ and $0.9 \%$, and of TLR $1.7 \%$ and $3.4 \%$, respectively.

While, in accordance with the results in precursor metallic scaffolds $^{3}$, no myocardial infarction beyond the 12-month follow-up was observed, there were two TLR beyond 12 months. The two TLR occurred on days 461 and 561 post procedure with angiographic diameter stenoses of $50 \%$ and $67 \%$ (per core laboratory); both patients were on DAPT, and the corresponding diameter stenoses at six months had been $43 \%$ and $32 \%$.

The fact that no definite or probable scaffold thrombosis was observed is encouraging, and is in line with the absence of scaffold thrombosis for previous versions of metal absorbable scaffolds $^{3,4}$. Notably, DAPT was recommended for at least six months post procedure in our series while for some more recent trials with polymeric scaffolds $\geq 12$ months of DAPT was recommended ${ }^{10,21}$. Potential reasons for the absence of scaffold thrombosis have been discussed previously ${ }^{7,21}$. In brief, no intraluminal mass was detected by optical coherence tomography in BIOSOLVE-II at six and 12 months and no malapposed struts were detected at six months, when scaffold struts were already well embedded into the vessel wall (Figure 3). With its $95 \%$ absorption at 12 months, a late acquired malapposition of our present metal scaffold is unlikely. Furthermore, the surface of the laser-polished DREAMS $2 \mathrm{G}$ is smooth, and strut cross-sections are rectangular with rounded edges, which may facilitate embedding into the vessel wall.

A recent study in porcine and rabbit models showed an increased endothelialisation and decreased thrombus formation for DREAMS $2 \mathrm{G}$ compared to Absorb. Inflammation for DREAMS 2G peaked at 90 days and decreased thereafter; at one and two years, inflammation was lower for DREAMS $2 \mathrm{G}$ versus an everolimus-eluting cobalt-chromium stent ${ }^{22}$. Furthermore, recent in vitro tests showed an improved deliverability of DREAMS $2 \mathrm{G}$ as compared to the Absorb BRS due to the metallic properties of DREAMS 2G, with less bending stiffness despite higher radial strength, indicating a better vessel conformability and no time-dependent recoil of DREAMS $2 \mathrm{G}$ in contrast to Absorb and DESolve ${ }^{23}$.

Although the recently propagated "4P" strategy (patient selection, predilatation, proper sizing and post-dilatation) was not 


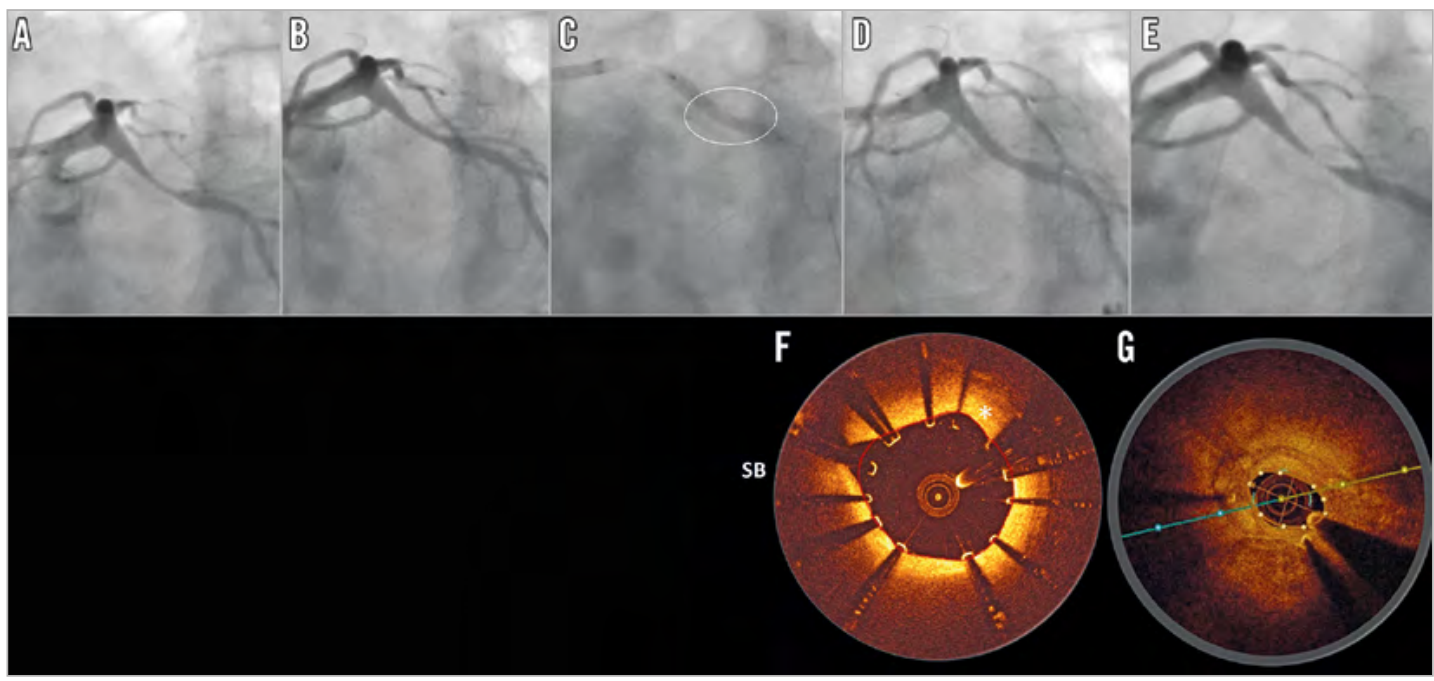

Figure 2. Angiographic and OCT results of a case that required target lesion revascularisation. Angiographic images of the left circumflex (A) pre-procedure, (B) after predilatation, $(C)$ after scaffold implantation (the circle marks the area of incomplete expansion), (D) post procedure, and (E) at 84 days post implant. (F) Post-procedure OCT image (incomplete strut apposition from 9 to 11 o'clock, 330 microns), and (G) at 84 days post implant (marked compression in the area of the original eccentric lesion with significant neointimal hyperplasia). OCT: optical coherence tomography; SB: side branch

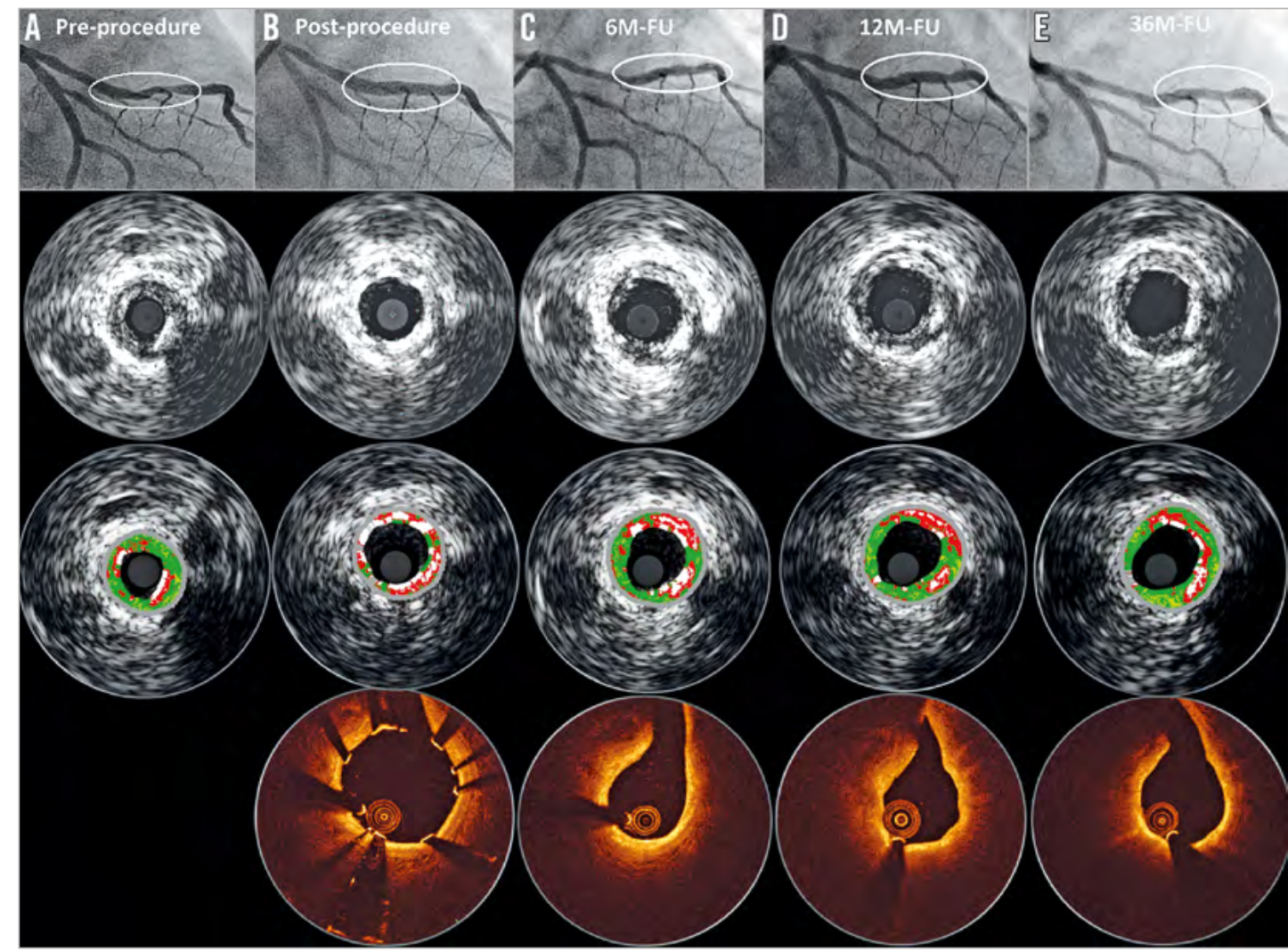

Figure 3. Serial quantitative angiographic, intravascular ultrasound and OCT results of a patient with DREAMS 2G implantation. A) A lesion in the mid left anterior descending (type B2, length $14 \mathrm{~mm}$, diameter $2.8 \mathrm{~mm}$, diameter stenosis $80 \%$ by visual estimate). Predilatation was conducted with a $3.0 \times 12 \mathrm{~mm}$ semi-compliant balloon. Thereafter, a DREAMS $2 G$ scaffold $(3.0 \times 20 \mathrm{~mm})$ was implanted. Post-dilatation was performed with a $3.0 \times 12 \mathrm{~mm}$ semi-compliant balloon. B) Post-procedure OCT and intravascular ultrasound demonstrate a good conformability to the vessel and a metallic appearance of DREAMS 2G. C) At six months, the degradation of the scaffold is detectable, and the struts covering the side branch have disappeared. D) At 12 months, OCT shows homogeneous neointima formation. E) Preservation of the lumen without any restenosis at 36 months. FU: follow-up; M: month; OCT: optical coherence tomography 
Table 3. Target lesion failure events up to 6 (BIOSOLVE-II/II) and 24 months (BIOSOLVE-II).

\begin{tabular}{|c|c|c|c|}
\hline Event & Study & $\begin{array}{l}\text { Post-procedure } \\
\text { day }\end{array}$ & Description \\
\hline Cardiac death 1 & BIOSOLVE-III & 2 & $\begin{array}{l}\text { Hospitalisation for subacute anterior ST-elevation myocardial infarction during the index } \\
\text { stay. In a first procedure the ostial left anterior descending artery was treated with a DES. } \\
\text { Echocardiography showed extensive anterior akinesia. A few days later, enzymes had } \\
\text { returned to normal and the patient received a DREAMS } 2 \mathrm{G} \text { in the right coronary artery. } \\
\text { One day after discharge the patient was found dead. The autopsy showed no thrombosis in } \\
\text { the coronary tree, especially not at the scaffold site. According to the clinical events } \\
\text { committee, the patient most likely died of ventricular arrhythmia due to the previous } \\
\text { myocardial infarction. }\end{array}$ \\
\hline Cardiac death 2 & BIOSOLVE-II & 134 & Unwitnessed death, no autopsy available. \\
\hline Cardiac death 3 & BIOSOLVE-II & 395 & $\begin{array}{l}\text { Unwitnessed death, patient died in his sleep without preceding symptoms, no autopsy } \\
\text { available. }\end{array}$ \\
\hline TV-MI & BIOSOLVE-II & 0 & Due to temporary no-reflow after scaffold implantation. \\
\hline TLR 1 & BIOSOLVE-II & 84 & $\begin{array}{l}\text { (Figure 2). RVD } 3.5 \mathrm{~mm} \text {, lesion length } 15.0 \mathrm{~mm} \text {, predilatation } 3.0 \times 15 \mathrm{~mm} \text { scoring } \\
\text { balloon, scaffold } 3.0 \times 20 \mathrm{~mm} \text {, post-dilatation } 3.0 \times 15 \mathrm{~mm} \text { NC balloon, } 16 \mathrm{~atm} \text {, and } \\
3.5 \times 12 \mathrm{~mm} \text { NC balloon, } 10 \text { atm, post-procedure in-scaffold DS: } 23 \% \text {. } \\
\text { Day } 84 \text { : angina (on exertion), in-scaffold DS } 81 \% \text {, treatment with } 3.5 \mathrm{~mm} \text { DES, post- } \\
\text { dilation with } 4.0 \text { and } 4.5 \mathrm{~mm} \text { balloon. }\end{array}$ \\
\hline TLR 2 & BIOSOLVE-III & 161 & $\begin{array}{l}\text { RVD } 2.9 \mathrm{~mm} \text {, lesion length } 11.0 \mathrm{~mm} \text {, predilatation } 3.0 \times 15 \mathrm{~mm} \text { NC balloon, scaffold: } \\
3.5 \times 25 \mathrm{~mm} \text {, no post-dilatation performed, post-procedure in-scaffold DS: } 6 \% \text {. } \\
\text { Day } 161 \text { : stable angina class III, DS: } 55 \% \text {, diagnostics excluded acute coronary } \\
\text { syndrome, treatment with DES. }\end{array}$ \\
\hline TLR 3 & BIOSOLVE-II & 180 & $\begin{array}{l}\text { RVD } 2.6 \mathrm{~mm} \text {, lesion length } 12.7 \mathrm{~mm} \text {, predilatation } 2.5 \times 15 \mathrm{~mm} \mathrm{NC} \text { balloon, scaffold } \\
3.0 \times 20 \mathrm{~mm} \text {, no post-dilatation, post-procedure DS: } 10 \% \text {. } \\
\text { Day } 180 \text { : ongoing angina, DS: } 54 \% \text {, treatment with } 3.0 \times 24 \mathrm{~mm} \text { DES. }\end{array}$ \\
\hline TLR 4 & BIOSOLVE-II & 461 & $\begin{array}{l}\text { RVD } 2.6 \mathrm{~mm} \text {, lesion length } 7.8 \mathrm{~mm} \text {, predilatation } 3.0 \times 12 \mathrm{~mm} \mathrm{NC} \text { balloon, scaffold: } \\
3.0 \times 20 \mathrm{~mm} \text {, post-dilatation } 3.5 \times 15 \mathrm{~mm} \text { NC balloon, } 24 \mathrm{~atm} \text {, post-procedure in-scaffold } \\
\text { DS: } 18 \% \text {. } \\
\text { Day 461: angina, in-scaffold DS } 50 \% \text {, treatment with } 3.0 \times 24 \mathrm{~mm} \text { DES. }\end{array}$ \\
\hline TLR 5 & BIOSOLVE-II & 561 & $\begin{array}{l}\text { RVD } 2.3 \mathrm{~mm} \text {, lesion length } 12.8 \mathrm{~mm} \text {, predilatation } 2.5 \times 15 \mathrm{~mm} \text { semi-compliant balloon, } \\
\text { scaffold: } 3.0 \times 20 \mathrm{~mm} \text {, post-dilatation } 3.0 \times 12 \mathrm{~mm} \text { NC balloon, } 18 \mathrm{~atm} \text {, post-procedure } \\
\text { in-scaffold DS: } 12 \% \text {. } \\
\text { Day } 561 \text { : positive stress test and chest pain, in-scaffold DS: } 67 \% \text {, treatment with } \\
2.25 \times 32 \mathrm{~mm} \text { DES. }\end{array}$ \\
\hline
\end{tabular}

DES: drug-eluting stent; DS: diameter stenosis; NC: non-compliant, RVD: reference vessel diameter; TLR: clinically driven target lesion revascularisation; TV-MI: target vessel myocardial infarction

implemented in both studies, the outcomes of BIOSOLVE-II and BIOSOLVE-III are favourable. In Figure 2, the case example of a restenosis shows that the development of the restenosis may be related to insufficient predilatation (panel B); during scaffold implantation, the balloon was not fully expanded at the site of the previous eccentric stenosis (panel C). Furthermore, the postprocedure angiographic image (panel D) suggests undersizing of the scaffold and insufficient post-dilation, which is also supported by the respective OCT frame that showed malapposed and non-embedded struts (panel F). Finally, during treatment of the restenosis, a $3.5 \mathrm{~mm}$ DES failed to gain full expansion, requiring post-dilatations with non-compliant balloons up to a nominal diameter of $4.5 \mathrm{~mm}$.

Meanwhile, predilatation with a non-compliant balloon in a 1:1 balloon-to-artery ratio is recommended. Moreover, post-dilatation with a non-compliant balloon up to $0.5 \mathrm{~mm}$ larger than the implanted scaffold with pressures $>16$ atm is recommended unless an optimal implantation result is confirmed by intracoronary imaging. The current treatment recommendations are summarised in a recently published preliminary expert consensus paper for metal scaffolds that particularly emphasises meticulous vessel preparation, precise sizing, imaging-guided implantation during the initial learning curve, and careful deployment and assessment of the scaffold ${ }^{12}$.

\section{Limitations}

Our series has several limitations. The fact that predominantly patients with limited clinical and anatomical complexity were included restricts the study interpretation to these patient and lesion characteristics. The lack of a control arm hampers the comparison to other devices; a randomised controlled trial would be needed. Furthermore, data on more patients are required to allow a robust assessment of rare events such as scaffold thrombosis. Routine angiographic follow-up at 24 months would have been of great interest. At least, we amended the current BIOSOLVE-II study protocol to obtain angiographic follow-up data at three years.

\section{Conclusions}

The present analysis provides additional evidence on the safety of DREAMS 2G (Magmaris; Biotronik) in a population with predominantly non-complex lesions. Clinical outcomes are favourable 
with low TLF rates up to two years. The absence of definite or probable scaffold thrombosis is promising, but requires confirmation in larger patient cohorts.

\section{Impact on daily practice}

The DREAMS 2G metal BRS has obtained CE approval in June 2016 with the commercial name Magmaris. Our data add further confirmation of the safety and performance of this novel scaffold: in particular (with the limitation of only 182 patients implanted), no definite or probable scaffold thrombosis was observed. Utmost care should be taken with respect to patient selection, device sizing, sufficient lesion preparation and post-dilatation to ensure good clinical outcomes with this novel technology.

\section{Acknowledgements}

We thank Beatrix Doerr for her expert medical writing assistance.

\section{Funding}

This study was funded by Biotronik AG, Bülach, Switzerland.

\section{Conflict of interest statement}

M. Haude reports study grants and lecture fees from Biotronik, Abbott Vascular, Cardiac Dimensions, Medtronic, Volcano, and Lilly. C. von Birgelen reports institutional research grants from AstraZeneca, Biotronik, Boston Scientific, and Medtronic, and that he has been an unpaid consultant to device manufacturing companies, among them Biotronik. A. Abizaid is a consultant to and has received research grants from Boston Scientific, Abbott Vascular, Elixir Medical and Reva Medical. N.M. Van Mieghem and the Erasmus Medical Center have received research grants from Abbott Vascular, Boston Scientific, Medtronic, Claret Medical and PulseCath. S. Verheye is a consultant of Elixir and Neovasc. R. Tölg reports receiving consultant fees and speakers honoraria from Abbott Vascular and Biotronik. R. Waksman is a consultant of Abbott Vascular, Amgen, Biosensors International, Biotronik, Boston Scientific, Corindus, Lifetech Medical, Medtronic Vascular, Philips Volcano, and Symetis, acts for the speakers bureau of AstraZeneca, and receives grant support from Biosensors International, Biotronik, Boston Scientific, Edwards Lifesciences, and Abbott Vascular. The other authors have no conflicts of interest to declare.

\section{References}

1. Waksman R. Promise and challenges of bioabsorbable stents. Catheter Cardiovasc Interv. 2007;70:407-14.

2. Eggebrecht H, Rodermann J, Hunold P, Schmermund A, Böse D, Haude M, Erbel R. Images in cardiovascular medicine. Novel magnetic resonance-compatible coronary stent: the absorbable magnesium-alloy stent. Circulation. 2005;112:e303-4.

3. Haude M, Erbel R, Erne P, Verheye S, Degen H, Vermeersch P, Weissman N, Prati F, Bruining N, Waksman R, Koolen J. Safety and performance of the DRug-Eluting Absorbable Metal Scaffold (DREAMS) in patients with de novo coronary lesions: 3-year results of the prospective, multicentre, first-in-man BIOSOLVE-I trial. EuroIntervention. 2016;12:e160-6.

4. Waksman R, Erbel R, Di Mario C, Bartunek J, de Bruyne B, Eberli FR, Erne P, Haude M, Horrigan M, Ilsley C, Böse D, Bonnier H, Koolen J, Lüscher TF, Weissman NJ; PROGRESSAMS (Clinical Performance Angiographic Results of Coronary Stenting with Absorbable Metal Stents) Investigators. Early- and long-term intravascular ultrasound and angiographic findings after bioabsorbable magnesium stent implantation in human coronary arteries. JACC Cardiovasc Interv. 2009;2:312-20.

5. von Birgelen C, Kok MM, van der Heijden LC, Danse PW, Schotborgh CE, Scholte M, Gin RM, Somi S, van Houwelingen KG, Stoel MG, de Man FH, Louwerenburg J, Hartmann M, Zocca P, Linssen GC, van der Palen J, Doggen CJ, Löwik MM. Very thin strut biodegradable polymer everolimus-eluting and sirolimus-eluting stents versus durable polymer zotarolimus-eluting stents in allcomers with coronary artery disease (BIO-RESORT): a three-arm, randomised, non-inferiority trial, Lancet. 2016;388:2607-2617.

6. Windecker S, Haude M, Neumann FJ, Stangl K, Witzenbichler B, Slagboom T, Sabate M, Goicolea J, Barragan P, Cook S, Piot C, Richardt G, Merkely B, Schneider H, Bilger J, Erne P, Waksman R, Zaugg S, Juni P, Lefèvre T. Comparison of a novel biodegradable polymer sirolimus-eluting stent with a durable polymer everolimus-eluting stent: results of the randomized BIOFLOW-II trial. Circ Cardiovasc Interv. 2015;8:e01441.

7. Haude $\mathrm{M}$, Ince $\mathrm{H}$, Abizaid A, Toelg R, Lemos PA, von Birgelen C, Christiansen EH, Wijns W, Neumann FJ, Kaiser C, Eeckhout E, Lim ST, Escaned J, Onuma Y, Garcia-Garcia HM, Waksman R. Sustained safety and performance of the second-generation drug-eluting absorbable metal scaffold in patients with de novo coronary lesions: 12-month clinical results and angiographic findings of the BIOSOLVE-II first-in-man trial. Eur Heart J. 2016;37:2701-9.

8. Toyota T, Morimoto T, Shiomi H, Yoshikawa Y, Yaku H, Yamashita Y, Kimura T. Very Late Scaffold Thrombosis of Bioresorbable Vascular Scaffold: Systematic Review and a MetaAnalysis. JACC Cardiovasc Interv. 2017;10:27-37.

9. Räber L, Brugaletta S, Yamaji K, O’Sullivan CJ, Otsuki S, Koppara T, Taniwaki M, Onuma Y, Freixa X, Eberli FR, Serruys PW, Joner M, Sabaté M, Windecker S. Very Late Scaffold Thrombosis: Intracoronary Imaging and Histopathological and Spectroscopic Findings. J Am Coll Cardiol. 2015;66:1901-14.

10. Wykrzykowska JJ, Kraak RP, Hofma SH, van der Schaaf RJ, Arkenbout EK, IJsselmuiden AJ, Elias J, van Dongen IM, Tijssen RY, Koch KT, Baan J Jr, Vis MM, de Winter RJ, Piek JJ, Tijssen JG, Henriques JP; AIDA Investigators. Bioresorbable Scaffolds versus Metallic Stents in Routine PCI. $N$ Engl J Med. 2017;376:2319-28.

11. Haude M, Ince H, Abizaid A, Toelg R, Lemos PA, von Birgelen C, Christiansen EH, Wijns W, Neumann FJ, Kaiser C, Eeckhout E, Lim ST, Escaned J, Garcia-Garcia HM, Waksman R. Safety and performance of the second-generation drug-eluting 
absorbable metal scaffold in patients with de-novo coronary artery lesions (BIOSOLVE-II): 6 month results of a prospective, multicentre, non-randomised, first-in-man trial. Lancet. 2016; 387:31-9.

12. Fajadet J, Haude M, Joner M, Koolen J, Lee M, Tolg R, Waksman R. Magmaris preliminary recommendation upon commercial launch: a consensus from the expert panel on 14 April 2016. EuroIntervention. 2016;12:828-33.

13. Moussa ID, Klein LW, Shah B, Mehran R, Mack MJ, Brilakis ES, Reilly JP, Zoghbi G, Holper E, Stone GW. Consideration of a new definition of clinically relevant myocardial infarction after coronary revascularization: an expert consensus document from the Society for Cardiovascular Angiography and Interventions (SCAI). J Am Coll Cardiol. 2013;62:1563-70.

14. Cutlip DE, Windecker S, Mehran R, Boam A, Cohen DJ, van Es GA, Steg PG, Morel MA, Mauri L, Vranckx P, McFadden E, Lansky A, Hamon M, Krucoff MW, Serruys PW; Academic Research Consortium. Clinical end points in coronary stent trials: a case for standardized definitions. Circulation. 2007;115:2344-51.

15. Abizaid A, Costa RA, Schofer J, Ormiston J, Maeng M, Witzenbichler B, Botelho RV, Costa JR Jr, Chamié D, Abizaid AS, Castro JP, Morrison L, Toyloy S, Bhat V, Yan J, Verheye S. Serial Multimodality Imaging and 2-Year Clinical Outcomes of the Novel DESolve Novolimus-Eluting Bioresorbable Coronary Scaffold System for the Treatment of Single De Novo Coronary Lesions. JACC Cardiovasc Interv. 2016;9:565-74.

16. Lipinski MJ, Escarcega RO, Baker NC, Benn HA, Gaglia J, Torguson R, Waksman R. Scaffold Thrombosis After Percutaneous Coronary Intervention With ABSORB Bioresorbable Vascular Scaffold: A Systematic Review and Meta-Analysis. JACC Cardiovasc Interv. 2016;9:12-24.

17. Onuma Y, Sotomi Y, Shiomi H, Ozaki Y, Namiki A, Yasuda S, Ueno T, Ando K, Furuya J, Igarashi K, Kozuma K, Tanabe K, Kusano H, Rapoza R, Popma JJ, Stone GW, Simonton C,
Serruys PW, Kimura T. Two-year clinical, angiographic, and serial optical coherence tomographic follow-up after implantation of an everolimus-eluting bioresorbable scaffold and an everolimus-eluting metallic stent: insights from the randomised ABSORB Japan trial. EuroIntervention. 2016;12:1090-1101.

18. Chevalier B, Onuma Y, van Boven AJ, Piek JJ, Sabaté M, Helqvist S, Baumbach A, Smits PC, Kumar R, Wasungu L, Serruys PW. Randomised comparison of a bioresorbable everolimus-eluting scaffold with a metallic everolimus-eluting stent for ischaemic heart disease caused by de novo native coronary artery lesions: the 2-year clinical outcomes of the ABSORB II trial. EuroIntervention. 2016;12:1102-1107.

19. Mukherjee D. Device Thrombosis with Bioresorbable Scaffolds. N Engl J Med. 2017;376:2388-9.

20. Byrne RA, Serruys PW, Baumbach A, Escaned J, Fajadet J, James S, Joner M, Oktay S, Juni P, Kastrati A, Sianos G, Stefanini GG, Wijns W, Windecker S. Report of a European Society of Cardiology-European Association of Percutaneous Cardiovascular Interventions task force on the evaluation of coronary stents in Europe: executive summary. Eur Heart J. 2015;36: 2608-20.

21. Capodanno D, Angiolillo DJ. Antiplatelet Therapy After Implantation of Bioresorbable Vascular Scaffolds: A Review of the Published Data, Practical Recommendations, and Future Directions. JACC Cardiovasc Interv. 2017;10:425-437.

22. Waksman R, Zumstein P, Pritsch M, Wittchow E, Haude M, Lapointe-Corriveau C, Leclerc G, Joner M. Second-generation magnesium scaffold Magmaris: device design and preclinical evaluation in a porcine coronary artery model. EuroIntervention. 2017;13:440-9.

23. Schmidt W, Behrens P, Brandt-Wunderlich C, Siewert S, Grabow N, Schmitz KP. In vitro performance investigation of bioresorbable scaffolds - Standard tests for vascular stents and beyond. Cardiovasc Revasc Med. 2016;7:375-83. 